\title{
TRIGO: TRÊS ÉPOCAS DE SEMEADURA EM CAPÃO BONITO, SP, NO PERÍODO 1981-85 (1)
}

\author{
JOÃO CARLOS FELICIO $(2,6)$, CARLOS EDUARDO DE OLIVEIRA CAMARGO $(2,6)$, \\ MARCELO BENTO PAES DE CAMARGO $(3,6)$, JAIRO LOPES DE CASTRO $(4,6)$ \\ $\Theta$ BENEDITO DE CAMARGO BARROS $(5,6)$
}

\begin{abstract}
RESUMO
Neste trabalho, procurou-se estudar o comportamento de dezoito cultivares de trigo semeados em três épocas ( $3^{\circ}$ decêndio de março, $2^{\circ}$ decêndio de abril e $3^{\circ}$ decêndio de maio) na Estação Experimental de Capão Bonito, região Sul do Estado de São Paulo, no qüinqūênio 1981-85. Efetuaram-se, em cada época de semeadura, avaliaçōes de rendimento de grāos, resistência às doenças, altura das plantas, peso hectolifrico e de mil grãos. Estudou-se a disponibilidade hídrica do solo, através de balanços hidricos decendiais, considerando $125 \mathrm{~mm}$ como a capacidade de retenção de água no solo. Os resultados indicaram como melhor época de semeadura 21 a 31 de março. A ocorrência de moléstias foi altamente influenciada pelas condiçōes climáticas verificadas em cada ano, sobretudo a helmintosporiose. Os cultivares CNT 7, BR 1, Paraguay 281, CNT 8, BH 1146, IAC 18 e IAC 5 apresentaram as maiores produçōes de grãos nas semeaduras de 21 a 31 de março, não diferindo estatisticamente entre si. As correlações entre altura
\end{abstract}

(1) Parcialmente financiado pelo Convênio LAC/Cooperativas dos Produtores Rurais do Vale do Paranapanema/SA. Recebido para publicaçăo em 16 de junho de 1987 e aceito em 16 de maio de 1988. pinas (SP).

(2) Seção de Arroz e Cereais de Invemo, Instituto Agronómico (IAC), Caixa Postal 28, 13001 Cam-

(3) Seçāo de Climatologia Agrícola, IAC.

(4) Estaçāo Experimental de Capāo Bonito, IAC. pinas (SP).

(5) Seçāo de Doenças das Plantas Alimentícias Básicas e Olerícolas, Instituto Biológico, 13093 Cam-

(6) Com bolsa de pesquisa do CNPq. 
média e produção de grãos na primeira e na segunda época foram significativas, mostrando que, nessas condiçōes, os cultivares de porte mais alto foram também os mais produtivos. O peso de mil grãos foi o componente da produção que melhor expressou as diferenças de comportamento entre os cultivares estudados nas diferentes épocas de semeadura em todo o período.

Termos de indexação: trigo, cultivar, balanços hídricos, ferrugens-do-colmo e da-folha, helmintosporiose, aitura das plantas, peso de mil grãos.

\section{INTRODUÇÃO}

A época de semeadura do trigo no Brasil tem sido alvo de controvérsias entre os técnicos, constituindo uma das causas do malogro de inúmeras campanhas promovidas no passado entre nós, com a finalidade da implantação da triticultura.

Dessa maneira, se o agricultor se dispuser a cultivar trigo e solicitar uma informação no extremo Sul do Brasil, ele a obterá imediatamente, pois o período mais aconselhável para semeadura na regiāo Sul, na fronteira com o Uruguai, é junho. Se, porém, ele fizer a mesma pergunta em outros Estados, segundo TElXEIRA (1958), ficará meio desorientado: há partidários da semeadura cedo, enquanto outros continuam a aconselhar um largo espaço de meses que vai de fevereiro até agosto.

As maiores áreas mundiais de cultivo do trigo estão concentradas entre 30 e $35^{\circ}$ de latitude em ambos os hemisférios, de acordo com MOTA (1982), em climas considerados moderadamente secos, moderadamente úmidos e temperados. KALCKMANN et al. (1965) consideram que o clima das regiōes triticolas brasileiras tem sido um dos principais responsáveis pela instabilidade da produção; consideram também que a faixa paulista de trigo situa-se no Sul e Sudoeste do Estado, abrangendo os municípios de Assis, Buri, Itaberá, Itapeva, Itaporanga, Itararé, Maracaí, Regente Feijó e Rio Branco. Seu clima é classificado como Cfa, mesotérmico úmido sem estiagens, em que a temperatura média do mês mais quente é $22^{\circ} \mathrm{C}$, apresentando o mês mais seco $30 \mathrm{~mm}$ de chuvas.

Seria utopia dar condiçóes rígidas ou pouco variáveis para uma planta de trigo (BAYMA, 1960), de tão vasta área de distribuição geográfica. É possivel afirmar, entretanto, que na germinação da semente e no início do crescimento da planta, têm grande importância a temperatura e a umidade do ar e do solo, estas dependentes das chuvas.

A resistência às geadas é pequena após a mudança fisiológica para a iniciação da inflorescência e emersão da espiga (PAULSEN, 1968). As temperaturas de $1-2^{\circ} \mathrm{C}$ abaixo de zero causam, segundo BURGOS (1963), danos aos grãos, pois o trigo é suscetivel a essas condiçōes. 
Os principais problemas climáticos da triticultura na regiāo temperada, abaixo do paralelo $24^{\circ}$ Sul, são o excesso de umidade relativa do ar em setembro-outubro, a ocorrência de geadas no espigamento, de chuvas na colheita e de granizo, sendo as duas primeiras muito mais importantes que as duas últimas (MOTA, 1982).

Estudos para determinação das melhores épocas de semeadura de trigo em São Paulo, com base na probabilidade do atendimento e demanda hídrica (CAMARGO et al., 1985), mostraram que, para a região Sudoeste, a melhor época seriam as semeaduras precoces, ou seja, efetuadas de março até início de abril.

Na regiāo Sul do Estado de Sāo Paulo, a cultura de trigo (FELíCiO et al., 1986) vem apresentando grande variação de produtividade por ser semeada em abril, coincidindo o seu florescimento, em junho, com a época que apresenta as maiores probabilidades de geadas.

O presente trabalho foi conduzido de 1981 a 1985 na Estação Experimental de Capão Bonito, com a finalidade de avaliar a melhor época de semeadura na região Sul do Estado de São Paulo, localizada na faixa do trigo que, segundo KALCKMANN et al. (1965), é de três milhões de hectares, dos quais poderá ser cultivado um milhão de hectares, sendo que, deste, trezentos mil hectares apresentam condições favoráveis à cultura.

\section{MATERIAL E MÉTODOS}

Dezoito cultivares de trigo foram ensaiados em três épocas de semeadura; para a primeira, considerou-se o período compreendido pelo $3^{\circ}$ decêndio do mês de março; para a segunda, o $2^{\circ}$ decêndio de abril e, para a terceira, o $3^{\circ}$ decêndio de maio, abrangendo o qüinqüênio 1981-85, no município de Capāo Bonito, região Sul do Estado de São Paulo, localizado na latitude de $24^{\circ} 02^{\prime} S$., longitude $48^{\circ} 22^{\prime} \mathrm{W}$. e altitude de $702 \mathrm{~m}$.

Os cultivares estudados foram divididos quanto ao ciclo vegetativo da emergência à maturação, sendo considerados precoces os seguintes: $\mathrm{BH} 1146$, IAC 13, IAC 17, IAC 18, INIA 66, Nambu e El Pato, com ciclo de até 120 dias; de ciclo médio, com maturação de 121 a 135 dias: Alondra 46, IAC 5, IAPAR 1, PAT 24, PAT 7219 e BR 2, e acima de 136 dias: CNT 7, CNT 8, Moncho BSB, Paraguay 281 e BR 1.

Retiraram-se amostras do solo dos locais estudados e, de acordo com os resultados analíticos, efetuou-se a adubação através dos seguintes adubos: sulfato de amônio com $20 \%$ de $\mathrm{N}$, superfosfato simples com $20 \%$ de $\mathrm{P}_{2} \mathrm{O}_{5}$ e cloreto de potássio com $60 \%$ de $\mathrm{K}_{2} \mathrm{O}$, aplicados a lanço antes da semeadura e, posteriormente, incorporados ao solo.

A quantidade de fertilizante empregado nas diferentes épocas e anos baseou-se nas tabelas de adubação e calagem do Instituto Agronômico. 
O delineamento estatístico empregado foi de blocos ao acaso com quatro repetições por época no mesmo local.

As parcelas de cada ensaio foram constituídas de cinco linhas de $5 \mathrm{~m}$ de comprimento, espaçadas de $0,20 \mathrm{~m}$, deixando-se um espaço lateral entre cada parcela de $0,60 \mathrm{~m}$ e de $1 \mathrm{~m}$ entre blocos.

A semeadura foi feita na base de 80 sementes viáveis por metro linear de sulco, equivalendo a 400 sementes por metro quadrado.

Os dados termopluviométricos diários relativos aos periodos considerados foram obtidos no Posto Meteorológico da Estação Experimental de Capão Bonito, SP, representativo de toda a região estudada.

Efetuou-se a caracterização da disponibilidade hídrica no solo através de balanços hídricos decendiais (dez dias), segundo o método de THORNTHWAITE \& MATHER (1955), considerando $125 \mathrm{~mm}$ como capacidade de retenção de água no solo, e calcularam-se os balanços hídricos para os meses de março a outubro, referentes ao período 1981-85 (Figuras 1 a 5).

Para avaliar o comportamento dos cultivares com relação às principais doenças em condiçōes naturais de infecção, empregaram-se as seguintes escalas de leitura: para a ferrugem-do-colmo (Puccinia graminis Pers. f. sp. tritici Eriks et Henn.) e ferrugem-da-folha (Puccinia recondita Rob. ex. Desm. f. sp. tritici Eriks), efetuaram-se avaliações em planta adulta usando a escala modificada de Cobb, empregada por SCHRAM et al. (1974). É composta por um número que estima o ataque da moléstia no colmo e na folha, acrescido de uma letra simbolizando o tipo de reação: $S$ = suscetivel (uredossoro grande, coalescente, sem clorose); MS = moderadamente suscetivel (uredossoro médio); $M=$ intermediário (diversos tipos de reação); $M R=$ moderadamente resistente (uredossoro pequeno); $\mathrm{R}=\mathrm{re}-$ sistente (uredossoro minúsculo rodeado de áreas necróticas). As doenças que causam manchas nas folhas devido ao complexo septoriose mais helmintosporiose (Septoria sp. e Helminthosporium sp.) foram estimadas em porcentagem de área foliar infectada, observando-se as folhas superiores das plantas.

$\mathrm{Na}$ colheita, tomaram-se cinco linhas de cada parcela, área útil de $5 \mathrm{~m}^{2}$, submetendo-se os dados de produção à análise estatística, segundo o modelo para grupos de experimentos, de acordo com GOMES (1970).

A altura das plantas de cada cultivar foi medida no campo, levando-se em consideração a distância do nivel do solo ao ápice da espiga, mantendo-se a planta esticada.

\section{RESULTADOS E DISCUSSÃO}

A indefinição específica de nossas condições meteorológicas entre os anos limita ou favorece a produção paulista de trigo, como mostram os balanços hídricos decendiais referentes aos anos de 1981 a 1985 (Figuras 1 a 5). Verifica-se 
que, em 1981, ocorreram periodos com deficiências hídricas mais acentuadas em meados de agosto e setembro e, em junho e julho, períodos chuvosos, sem apresentarem, no entanto, excedentes hidricos acentuados. De 1982 a 1983, verificou-se um período de umidade excessiva respectivamente em junho-julho e maio-junho. Podem-se considerar como bem características as condições climáticas ocorridas em 1984 e 1985. O excesso de umidade para a triticultura se apresenta prejudicial, quanto aos periodos de estiagens prolongadas.

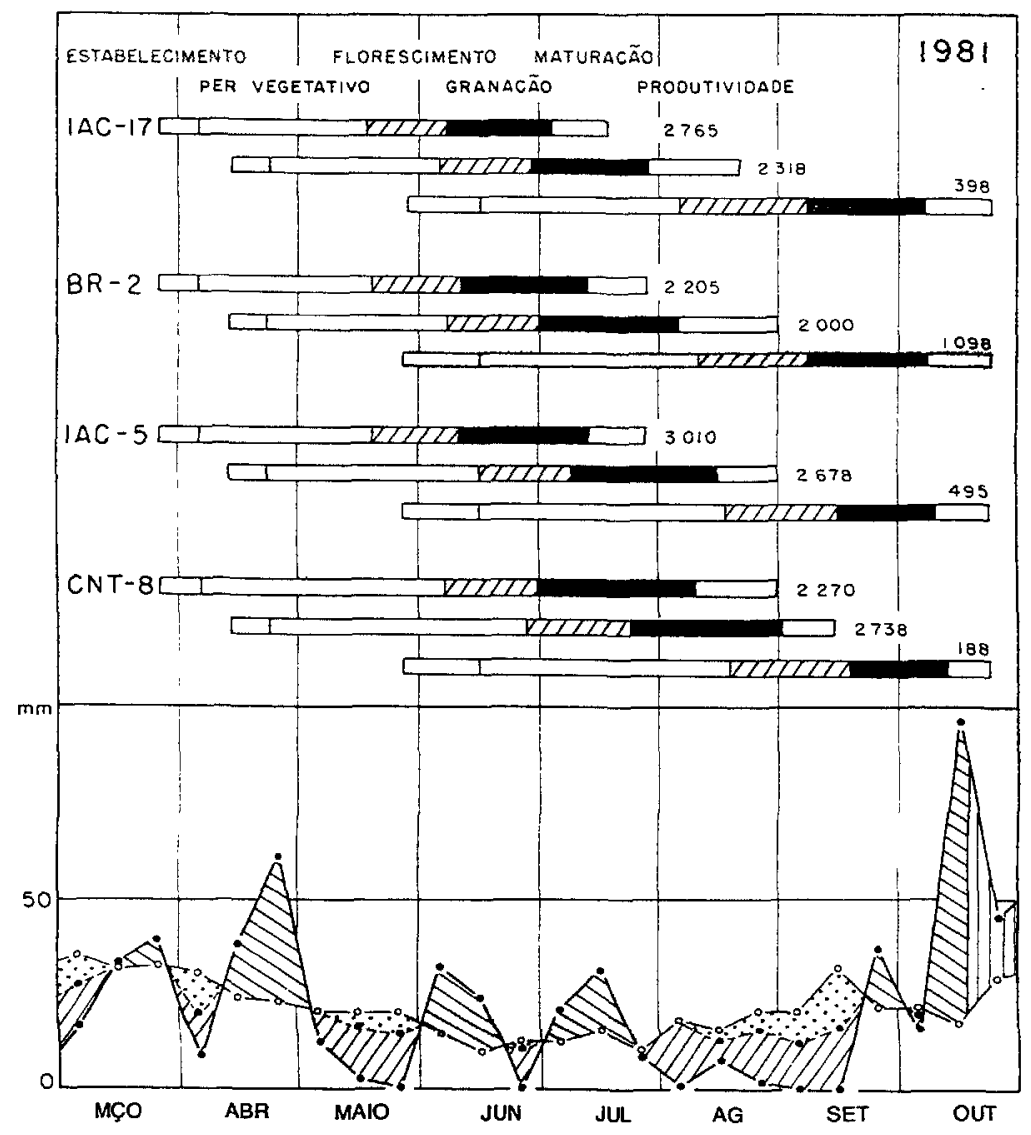

FIGURA 1. Balanço hídrico decendial, pelo método de THORNTHWAITE \& MATHER (1955) (125mm) e anotaçōes fenológicas dos cultivares de trigo IAC 17, BR 2, IAC 5 e CNT 8, durante $o$ ano de 1981. 


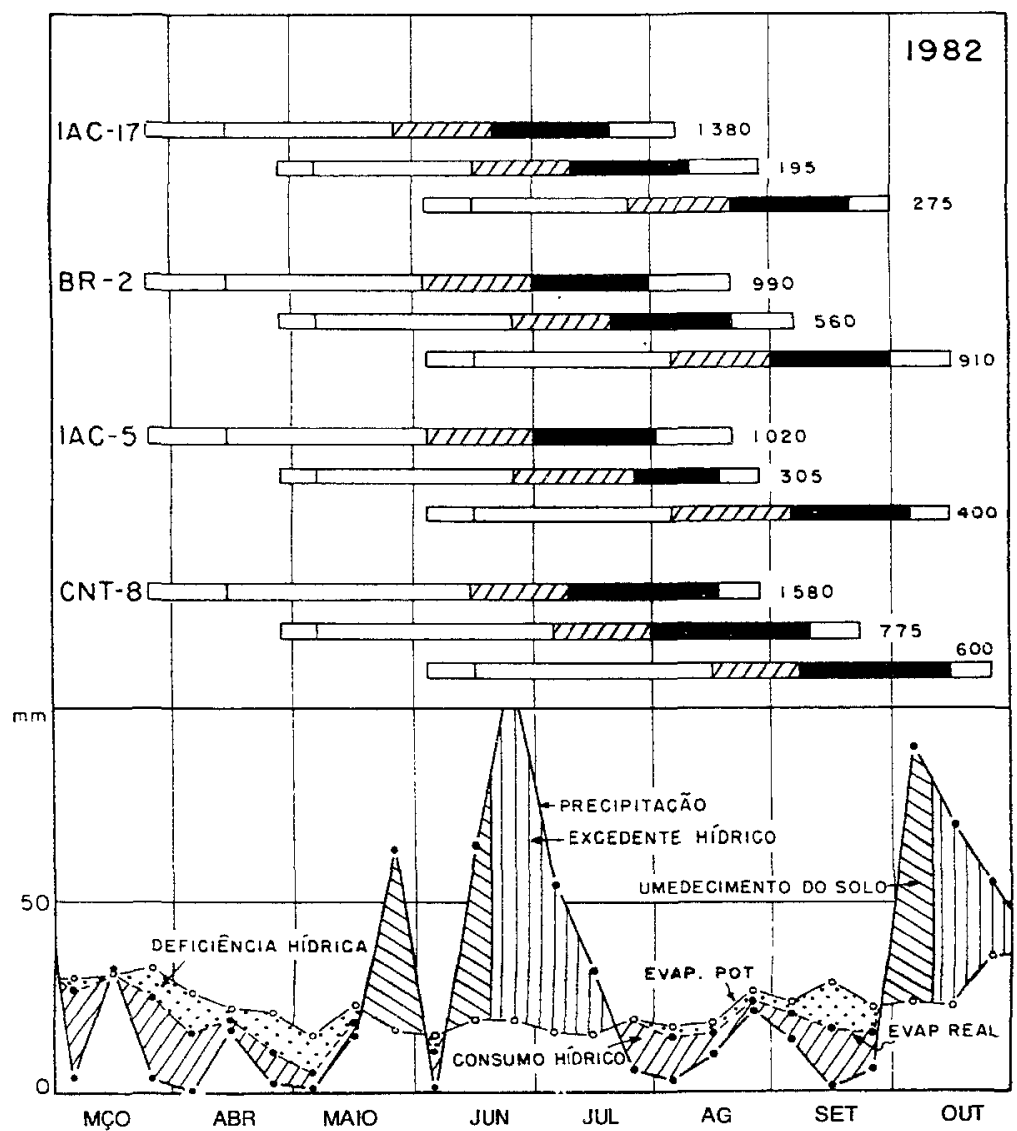

FIGURA 2. Balanço hídrico decendial, pelo método de THORNTHWAITE \& MATHER (1955) (125mm) e anotações fenológicas dos cultivares de trigo IAC 17, BR 2, IAC 5 e CNT 8, durante o ano de 1982.

No quadro 1, encontram-se os rendimentos médios de grãos de dezoito cultivares de trigo estudados em três épocas de semeadura, no município de Capão Bonito, no qüinqüênio 1981-85. Pelo quadro 2 - resultados da análise da variância dos ensaios - verifica-se que, entre as causas da variação estudadas, destacaram-se os efeitos altamente significativos obtidos para a época de semeadura $(\vartheta=35,90)$ e para anos $(\vartheta=45,68)$. Esses dados demonstram a variação que ocorre durante o período em que o trigo pode ser semeado na regiāo. Verifica-se também que houve efeitos altamente significativos para os cultivares estudados e para as interações cultivar $x$ época, época $x$ ano e cultivar $x$ ano. 


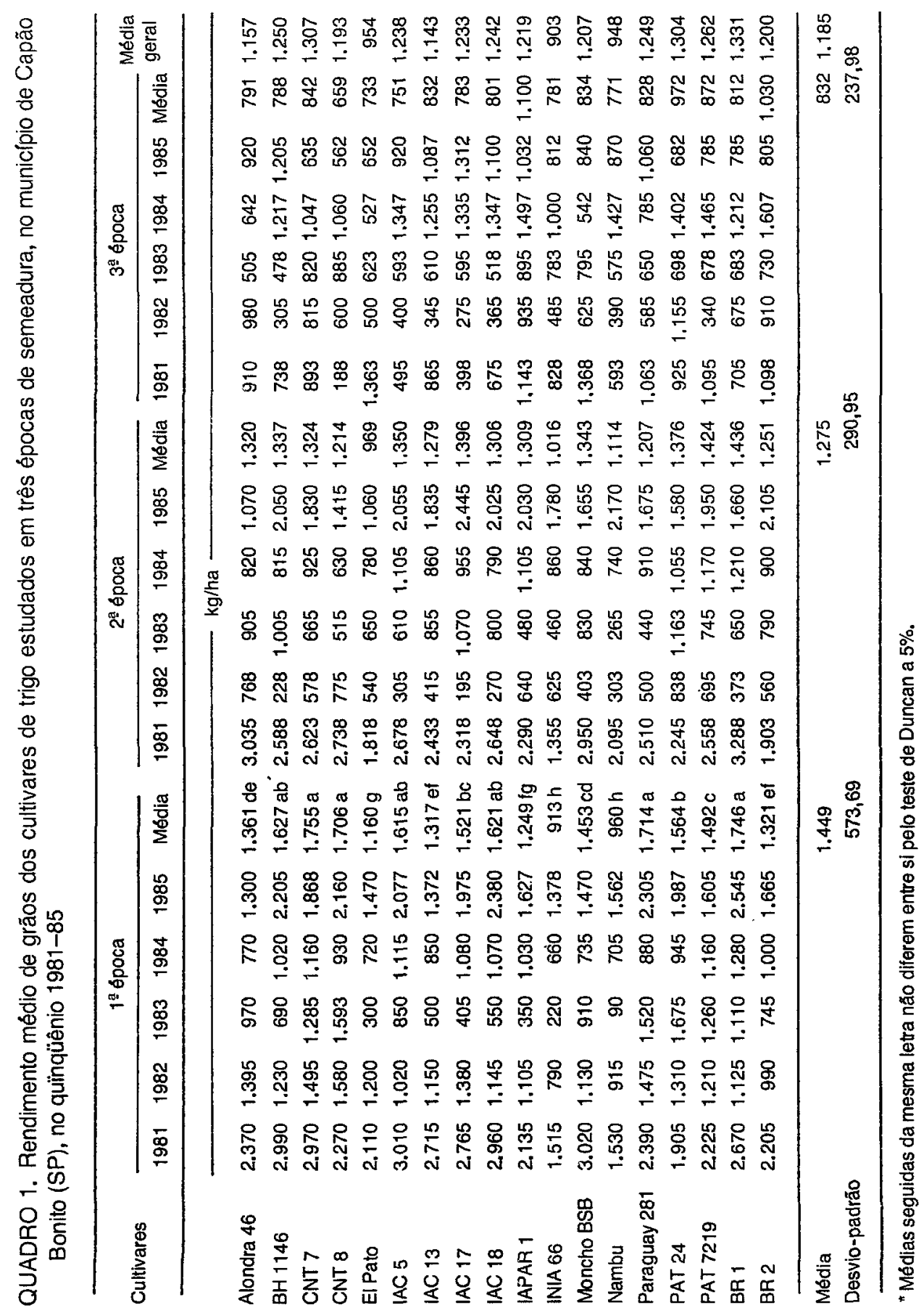




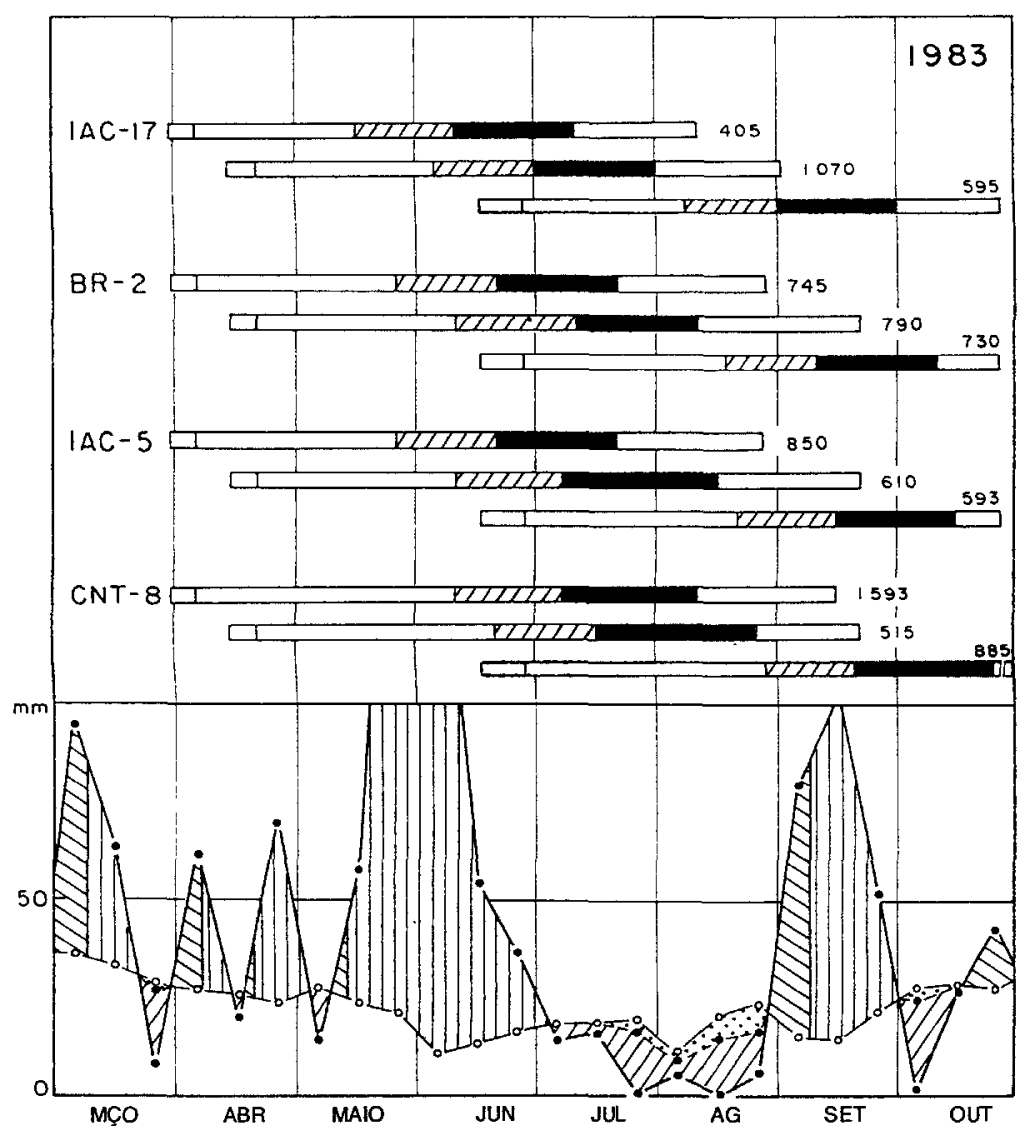

FIGURA 3. Balanço hídrico decendial, pelo método de THORNTHWAITE \& MATHER (1955) $(125 \mathrm{~mm})$ e anotaçōes fenológicas dos cultivares de trigo IAC 17, BR 2, IAC 5 e CNT 8, durante o ano de 1983.

Para entender melhor o estabelecimento da cultura e suas diversas fases até a colheita, serão considerados para análise quatro cultivares de trigo utilizados pelos agricultores na região (Figs. 1 a 5). $O^{\prime} I A C ~ 17$ ', considerado de ciclo precoce, apresentou produtividade média de grăos, em quilograma/hectare, dècrescente da $1^{a}$ para a $2^{a}$ época, enquanto na semeadura de $3^{a}$ época a sua produtividade foi $48,52 \%$ inferior à da primeira. O mesmo ocorreu com o 'IAC 5', considerado de ciclo médio. $\mathrm{O}$ 'BR 2', de ciclo médio, revelou melhor estabilidade em sua produção, sendo a diferença da $1^{\text {a }}$ para a $3^{\text {a }}$ época apenas de $22 \%$. A maior diferença ficou, entretanto, para os cultivares de ciclo tardio, representados pelo CNT 8, que apresentou uma redução de produtividade de 28,84 e $61,37 \%$ entre a $1^{\mathrm{a}}$ e a $2^{\mathrm{a}}$ época e a $1^{\mathrm{a}}$ e a $3^{\mathrm{a}}$ respectivamente. 


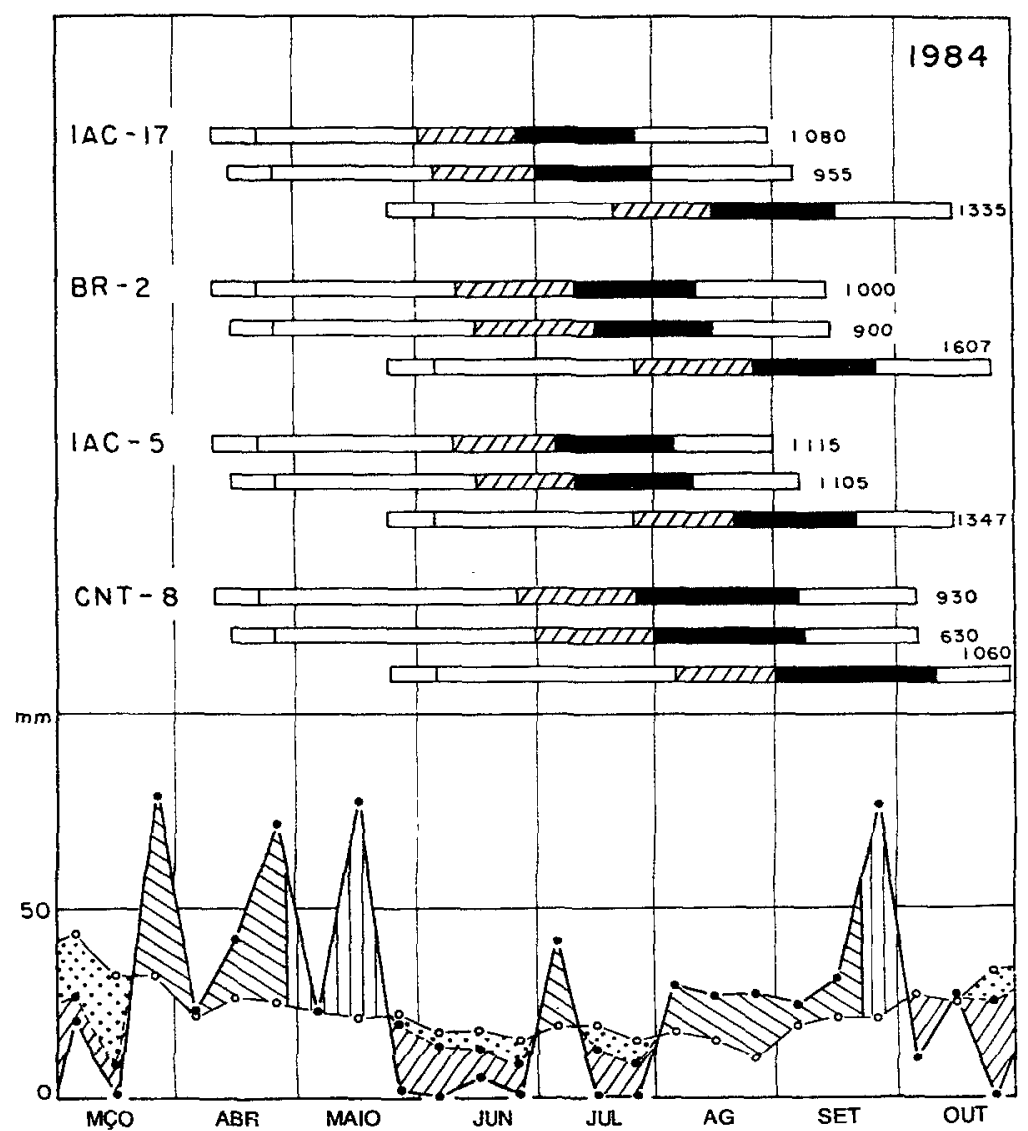

FIGURA 4. Balanço hídrico decendial, pelo método de THORNTHWAITE \& MATHER (1955) (125mm) e anotaçōes fenológicas dos cultivares de trigo IAC 17, BR 2, IAC 5 e CNT 8, durante o ano de 1984.

No quadro 3 encontram-se as temperaturas mínimas absolutas, em nivel decendial, de abril a setembro, para o qüinqüênio 1981-85: verifica-se que as temperaturas mais baixas ocorreram do $1^{\circ}$ decêndio de junho ao $1^{\circ}$ decêndio de agosto, podendo aparecer eventuais geadas no final de agosto, consideradas como tardias, porém com menor probabilidade de ocorrência.

De acordo com 0 expusto, as culturas semeadas no $3^{\circ}$ decêndio de março e de maio apresentam probabilidade de escape das geadas; segundo dados de Burgos, citado por MOTA (1982), o trigo é suscetível a danos por temperatura de 1 a $2^{\circ} \mathrm{C}$ abaixo de zero durante a floração e de 2 a $4^{\circ} \mathrm{C}$ abaixo de zero durante a formação do grão, condiçōes essas com maior probabilidade de ocorrência das semeaduras do $2^{\circ}$ decêndio de abril, quando as plantas se encontravam no estádio de pleno florescimento em junho-julho. 
QUADRO 2. Resultados parciais da análise da variância para rendimento de grãos dos cultivares de trigo, em três épocas de semeadura e em cinco anos de experimentação, no município de Capão Bonito (SP), no periodo 1981-85

\begin{tabular}{lrrr}
\hline Causa da variação & G.L. & Desvio-padrāo & V \\
\hline Cultivar (C) & 17 & 485,14 & $5,92^{* *}$ \\
Época (E) & 2 & 3020,23 & $35,90^{\star *}$ \\
Anos (A) & 4 & 3738,71 & $45,68^{* *}$ \\
Interação C x E & 34 & 342,81 & $4,18^{\star *}$ \\
Interação Ex A & 68 & 1880,18 & $22,97^{\star *}$ \\
Interação C X A & 8 & 355,41 & $4,34^{* *}$ \\
Interação T x Ex A & 136 & 81,84 & \\
\hline
\end{tabular}

** = Significativo ao nivel de $1 \%$.

QUADRO 3. Temperaturas mínimas absolutas em nivel decendial, de abril a setembro, referentes ao periodo 1981-85 para Capão Bonito (SP)

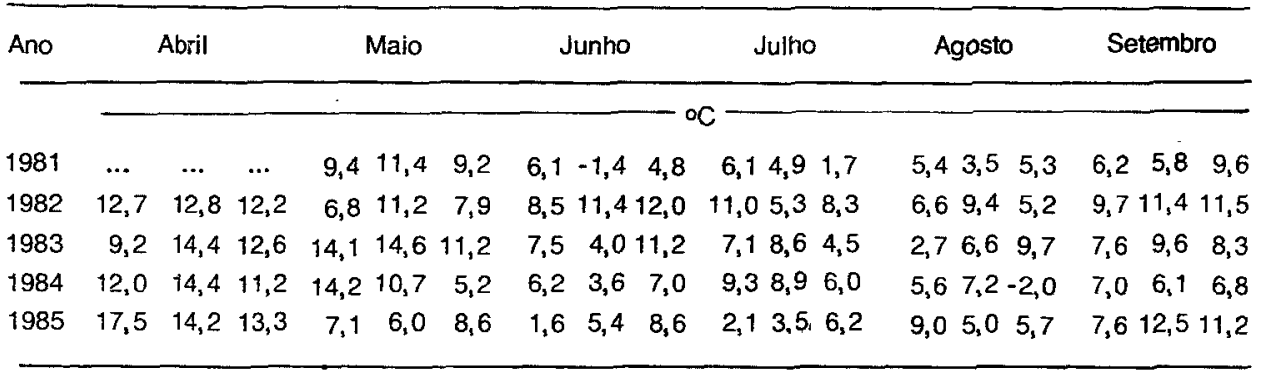

Fonte: Seção de Climatologia Agrícola, Instituto Agronômico.

... Não hå informação.

Verificou-se, portanto, que a primeira época de semeadura representou as condições ideais quanto ao clima da região para a produtividade de grãos, pois apresentou uma produtividade média de $1.449 \mathrm{~kg} / \mathrm{ha}$, diferindo das outras épocas pelo teste de Duncan a 5\% (Quadro 1).

Entre os cultivares estudados, pode-se destacar, na 1ㄹ época, CNT 7, BR 1, Paraguay 281, CNT 8, BH 1146, IAC 18 e IAC 5, que nāo diferiram entre si pelo teste de Duncan a $5 \%$. 


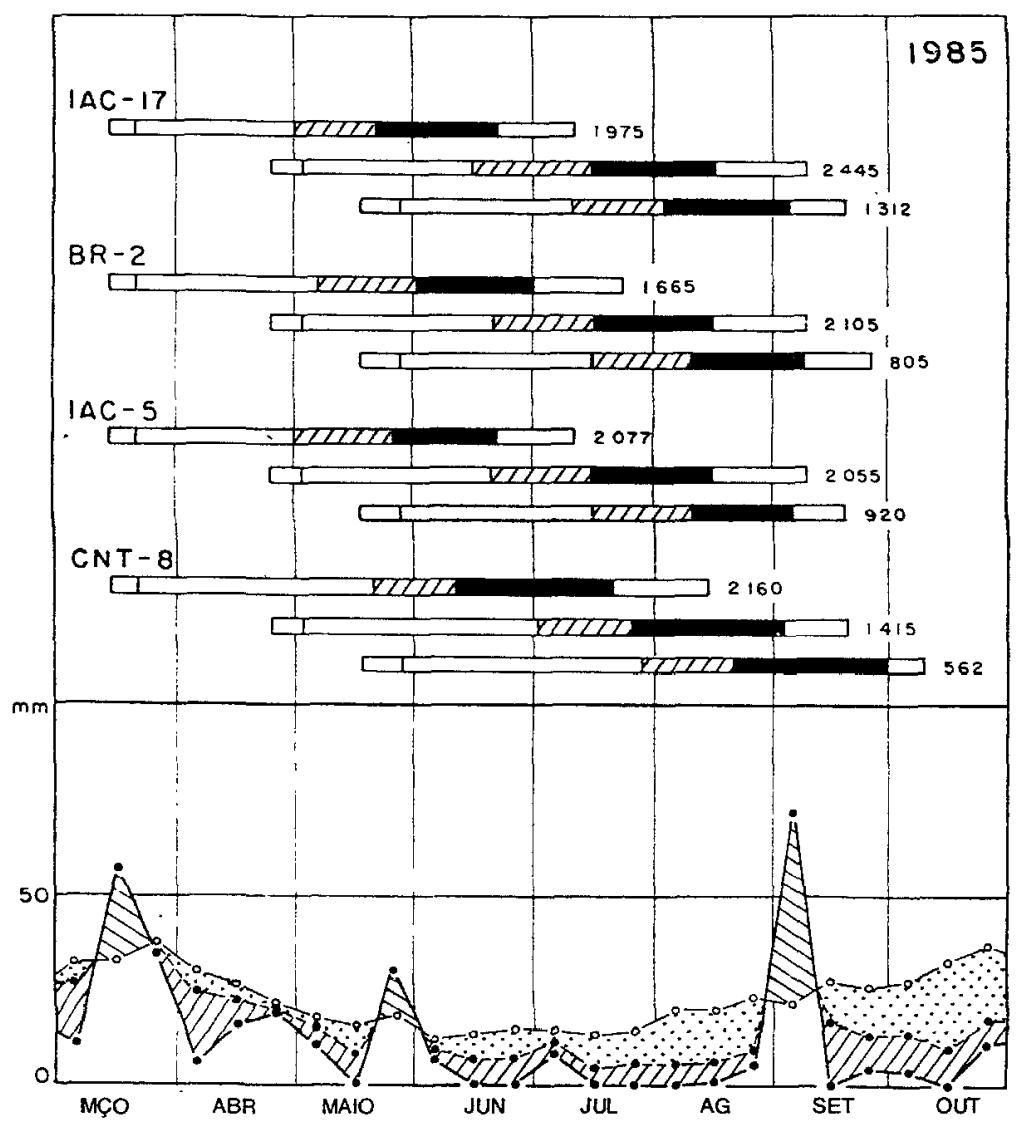

FIGURA 5. Balanço hídrico decendial, pelo método de THORNTHWAITE \& MATHER (1955) (125mm) e anotaçōes fenológicas dos cultivares de trigo IAC 17, BR 2, IAC 5 e CNT 8, durante o ano de 1985.

A correlação entre as produções médias de grãos dos cultivares estudados, em 1981-85, nas três épocas de semeadura consideradas, apresentou $r=$ 0,673 significativo a $1 \%$ entre a $1^{\text {a }}$ e a $2^{\text {a }}$ época; entretanto, entre a $1^{\text {a }}$ e a $3^{\mathrm{a}}, \mathrm{e}$ entre a $2^{\mathrm{a}}$ e a $3^{\mathrm{a}}$, as correlaçōes não foram significativas: $r=0,107$ e $r=0,296$ respectivamente.

A maior produtividade média de grāos para os anos em estudo, independente das épocas, foi de $1.910 \mathrm{~kg} / \mathrm{ha}$ para o de 1981 , diferindo das demais médias pelo teste de Duncan a $5 \%$, seguida de 1985 , com $1.508 \mathrm{~kg} / \mathrm{ha}$, e de 1984 , com $1.005 \mathrm{~kg} / \mathrm{ha}$, que diferiram de 1983 e 1982, considerados climaticamente inaptos à cultura devido ao excesso de uninidade, $766 \mathrm{~kg} / \mathrm{ha}$ e $741 \mathrm{~kg} / \mathrm{ha}$ respectivamente. 
QUADRO 4. Ocorrência de Puccinia recondita Rob. ex. Desm. sp. tritici Eriks (ferrugem-da-folha), em três épocas de semeadura, nos cultivares de trigo estudados no periodo 1981-85, no município de Capão Bonito (SP)

\begin{tabular}{|c|c|c|c|c|c|c|c|c|c|c|}
\hline \multirow{2}{*}{ Cultivares } & \multicolumn{3}{|c|}{1981} & \multicolumn{3}{|c|}{1982} & \multicolumn{3}{|c|}{1984} & \multirow{2}{*}{$\frac{1985}{\text { II época }}$} \\
\hline & Iépoca & II época & III época & lépoca & II Época & Ill época & lépoca & ll época & III época & \\
\hline Alondra 46 & 0 & 0 & $10 \mathrm{MR}$ & $20 \mathrm{MS}$ & $10 \mathrm{MS}$ & $10 \mathrm{MS}$ & $40 S$ & $30 \mathrm{~s}$ & $10 S$ & 0 \\
\hline $\mathrm{BH}^{-} 1146$ & $10 \mathrm{~S}$ & $10 \mathrm{~s}$ & $10 \mathrm{~S}$ & $20 \mathrm{~S}$ & $40 \mathrm{~S}$ & $20 \mathrm{~S}$ & $20 \mathrm{~S}$ & $5 S$ & $10 S$ & $5 \mathrm{MS}$ \\
\hline CNT 7 & $5 S$ & $5 s$ & $30 \mathrm{~S}$ & $20 \mathrm{~S}$ & $10 \mathrm{~S}$ & 105 & $10 S$ & $5 S$ & 105 & $20 \mathrm{~s}$ \\
\hline CNT 8 & TMS & $5 \mathrm{MS}$ & $10 \mathrm{MS}$ & $10 S$ & 0 & $40 \mathrm{MR}$ & 0 & 0 & 0 & $30 \mathrm{~s}$ \\
\hline El Pato & $10 \mathrm{~s}$ & $10 \mathrm{~s}$ & $5 S$ & $10 S$ & 0 & 0 & 0 & $5 S$ & $10 \mathrm{~S}$ & 0 \\
\hline IAC 5 & $5 S$ & $50 \mathrm{~S}$ & $20 \mathrm{~s}$ & $40 \mathrm{~S}$ & $40 \mathrm{~S}$ & $40 \mathrm{~S}$ & $5 \mathrm{~S}$ & $10 \mathrm{~s}$ & $5 S$ & $50 \mathrm{~S}$ \\
\hline IAC 13 & $5 S$ & $40 \mathrm{~S}$ & $30 \mathrm{~s}$ & $5 S$ & $50 \mathrm{~s}$ & $40 s$ & $10 S$ & $40 \mathrm{~S}$ & $40 S$ & $30 \mathrm{~s}$ \\
\hline IAC 17 & $5 S$ & $30 \mathrm{~S}$ & $20 \mathrm{~S}$ & $25 \mathrm{~S}$ & $30 \mathrm{~s}$ & $40 S$ & $30 \mathrm{~s}$ & $10 \mathrm{~S}$ & $10 \mathrm{~s}$ & $10 \mathrm{~S}$ \\
\hline IAC 18 & 0 & $5 S$ & 0 & $20 \mathrm{~S}$ & $10 \mathrm{~S}$ & $10 \mathrm{~s}$ & $10 S$ & $5 S$ & $30 \mathrm{~S}$ & 0 \\
\hline IAPAR 1 & 0 & 0 & 0 & 0 & 0 & 0 & 0 & 0 & 0 & 0 \\
\hline INIA 66 & $10 \mathrm{~S}$ & $40 \mathrm{~S}$ & $40 \mathrm{~S}$ & $5 S$ & $30 \mathrm{~s}$ & $20 \mathrm{~S}$ & $10 S$ & $10 S$ & $20 \mathrm{~S}$ & $10 \mathrm{~S}$ \\
\hline Moncho BSB & 0 & 0 & 0 & $5 S$ & 0 & $20 \mathrm{~S}$ & 0 & $5 S$ & $10 \mathrm{~S}$ & $5 \mathrm{MS}$ \\
\hline Nambu & 0 & $5 \mathrm{MS}$ & 0 & $20 \mathrm{~S}$ & 0 & 0 & 0 & TS & 0 & $5 S$ \\
\hline Paraguay 281 & $5 S$ & $30 \mathrm{MS}$ & $5 \mathrm{MS}$ & $20 S$ & 0 & $40 S$ & $10 \mathrm{~S}$ & $10 \mathrm{~S}$ & $5 S$ & $20 \mathrm{~s}$ \\
\hline PAT 24 & $20 \mathrm{~S}$ & $30 \mathrm{~s}$ & $30 \mathrm{~s}$ & $40 \mathrm{~S}$ & $40 \mathrm{~S}$ & $30 \mathrm{~s}$ & $20 S$ & $10 s$ & $20 \mathrm{~S}$ & $30 \mathrm{~s}$ \\
\hline PAT 7219 & $5 S$ & $10 \mathrm{~s}$ & $20 \mathrm{MS}$ & $20 \mathrm{~S}$ & $20 \mathrm{~S}$ & $20 \mathrm{~S}$ & $10 \mathrm{MS}$ & $10 S$ & $20 \mathrm{~S}$ & $30 \mathrm{~S}$ \\
\hline BR 1 & $10 \mathrm{MS}$ & $10 \mathrm{~S}$ & $10 \mathrm{~S}$ & $20 \mathrm{~S}$ & $20 \mathrm{~S}$ & $10 \mathrm{~S}$ & $5 S$ & $10 S$ & $20 \mathrm{~s}$ & 0 \\
\hline BR 2 & $10 \mathrm{~S}$ & $10 \mathrm{~s}$ & $20 \mathrm{~s}$ & $30 \mathrm{~s}$ & $50 \mathrm{~s}$ & $20 \mathrm{~S}$ & $5 S$ & $5 S$ & $30 \mathrm{~s}$ & 0 \\
\hline
\end{tabular}

As leituras de 1983 foram muito prejudicadas devido à ocorrência acima dos indices normais de helmintosporiose; portanto, năo foram inclufdas no quadro; en 1985, na semeadura de $1^{\text {a }}$ e $3^{\mathrm{a}}$ época, não ocorreu a doença.

$\mathrm{S}=$ suscetivel; $\mathrm{MS}=$ moderadamente suscetfvel; $\mathrm{MR}=$ moderadamente resistente; $\mathrm{t}=$ traço.

No quadro 4 encontra-se a freqüência da ferrugem-da-folha no período: somente o cultivar IAPAR 1 apresentou resistência à patogenicidade da moléstia, considerando que ataques severos ocorreram em 1983 e, principalmente, em 1982 (BARCELLOS, 1985). Os cultivares que apresentaram maior suscetibilidade ao patógeno causador da moléstia foram o IAC 5, IAC 13, IAC 17, INIA 66 e PAT 24.

A ocorrência de ferrugem-do-colmo - Quadro 5 - de acordo com as leituras realizadas no período, confirma os resultados obtidos por COELHO (1986), que mostrou existir nas diferentes regiōes alteraçōes de freqüência do agente causal da moléstia de acordo com o ano, podendo ocorrer o aparecimento de novas raças. Não apareceu a moléstia quando o experimento foi semeado nas três épocas de plantio de 1983 e 1984 e nas duas primeiras de 1985. Nas semeaduras efetuadas no $2^{\circ}$ decêndio de abril (2ª época de plantio), em 1981 e 1982, no $3^{\circ}$ decêndio de março, em 1982, e no $3^{\circ}$ decêndio de maio de $1981-85$, ocorreu com maior intensidade 0 ataque do fungo causador da ferrugem-do-colmo. Entre os cultivares que apresentaram maior suscetibilidade, aparecem o BH 1146, IAC 
5, IAC 17, IAC 18, Nambu e BR 1; com resistência moderada ao agente causal, os cultivares CNT 8, INIA 66 e PAT 24.

A ocorrencia de manchas foliares, causadas por Helminthosporium sp., Septoria nodorum Berk. e Septoria tritici Rob. ex. Desm., sofre muita influência da umidade na resistência dos cultivares aos organismos que causam essas moléstias, segundo LUZ (1982) e FELICIO et al. (1986). No quadro 6, verifica-se que a presença dos agentes causais de manchas foliares nas plantas de trigo foram muito mais intensas na $3^{a}$ época de semeadura de 1982 e $1^{a}$ época de 1983 , quando apareceram também nas espigas. Essas observações coincidiram nos períodos com precipitaçōes consideradas fora da média da regiāo para a época, proporcionando umidade excessiva que veio favorecer a incidência dessas moléstias acima dos seus índices normais anuais (Figuras 1 a 5). Não se verificou, portanto, resistência dos cultivares estudados a essa condição de ataque dos agentes causais das manchas foliares.

QUADRO 5. Ocorrência de Puccinia graminis Pers. f. sp. tritici Eriks. et Henn.(ferrugem-do-colmo) em três épocas de semeadura, nos cultivares de trigo estudados em 1981, 1982 e 1985 no município de Capão Bonito (SP)

\begin{tabular}{|c|c|c|c|c|c|c|}
\hline \multirow{2}{*}{ Cultivares } & \multicolumn{3}{|c|}{1981} & \multicolumn{2}{|c|}{1982} & \multirow{2}{*}{$\frac{1985}{\text { III época }}$} \\
\hline & l época & |l época & III época & I época & II época & \\
\hline Alondra 46 & 0 & $10 \mathrm{MR}$ & $20 \mathrm{MR}$ & $T S$ & 0 & TMS \\
\hline $\mathrm{BH} 1146$ & 0 & $20 \mathrm{~S}$ & $60 \mathrm{~S}$ & $60 \mathrm{~s}$ & $60 \mathrm{~S}$ & $80 S$ \\
\hline CNT 7 & 0 & $20 \mathrm{~S}$ & $10 \mathrm{~S}$ & $10 \mathrm{~S}$ & $10 \mathrm{~S}$ & $20 \mathrm{~S}$ \\
\hline CNT 8 & 0 & 0 & $T S$ & 0 & 0 & $10 \mathrm{~S}$ \\
\hline El Pato & 0 & $30 \mathrm{~S}$ & $10 \mathrm{MS}$ & $5 S$ & 0 & $30 \mathrm{~s}$ \\
\hline IAC 5 & $T S$ & $40 \mathrm{~S}$ & $60 \mathrm{~S}$ & $40 \mathrm{~S}$ & $40 \mathrm{~S}$ & $40 \mathrm{~S}$ \\
\hline IAC 13 & 0 & $5 R$ & $5 \mathrm{~S}$ & $5 \mathrm{~S}$ & $20 \mathrm{~S}$ & $20 \mathrm{~S}$ \\
\hline IAC 17 & 0 & $20 \mathrm{~S}$ & $40 \mathrm{~S}$ & $25 \mathrm{~S}$ & $60 \mathrm{~S}$ & $20 \mathrm{~S}$ \\
\hline IAC 18 & 0 & $40 \mathrm{~S}$ & $50 \mathrm{~S}$ & $50 \mathrm{~S}$ & $10 \mathrm{~S}$ & $40 S$ \\
\hline IAPAR 1 & 0 & 0 & $30 \mathrm{~S}$ & $10 \mathrm{~S}$ & 0 & $30 \mathrm{~S}$ \\
\hline INIA 66 & 0 & $5 R$ & 0 & 0 & 0 & $10 \mathrm{~S}$ \\
\hline Moncho BSB & 0 & $10 S$ & $30 \mathrm{~S}$ & $5 S$ & 0 & $20 \mathrm{~S}$ \\
\hline Nambu & 0 & $20 \mathrm{~S}$ & $50 \mathrm{~S}$ & $45 \mathrm{~S}$ & $10 \mathrm{MS}$ & $20 \mathrm{~S}$ \\
\hline Paraguay 281 & 0 & $5 \mathrm{R}$ & $20 \mathrm{~S}$ & $5 S$ & 0 & $80 \mathrm{~S}$ \\
\hline PAT 24 & 0 & $5 R$ & $5 S$ & TS & 0 & 0 \\
\hline РAT 7219 & 0 & 205 & $40 S$ & $15 \mathrm{~S}$ & 0 & $30 \mathrm{~s}$ \\
\hline BR 1 & $10 \mathrm{~S}$ & $40 \mathrm{~S}$ & $60 \mathrm{~S}$ & $40 \mathrm{~S}$ & $10 \mathrm{~S}$ & $70 \mathrm{~s}$ \\
\hline BR 2 & 0 & $5 \mathrm{MR}$ & $20 \mathrm{~S}$ & $10 \mathrm{~S}$ & $10 \mathrm{~S}$ & $30 \mathrm{~S}$ \\
\hline
\end{tabular}

$\mathrm{S}=$ suscetivel; $\mathrm{R}=$ resistente; $\mathrm{MR}=$ moderadamente resistente; $\mathrm{MS}=$ moderadamente suscetivel; $\quad \mathrm{T}=$ traço. 


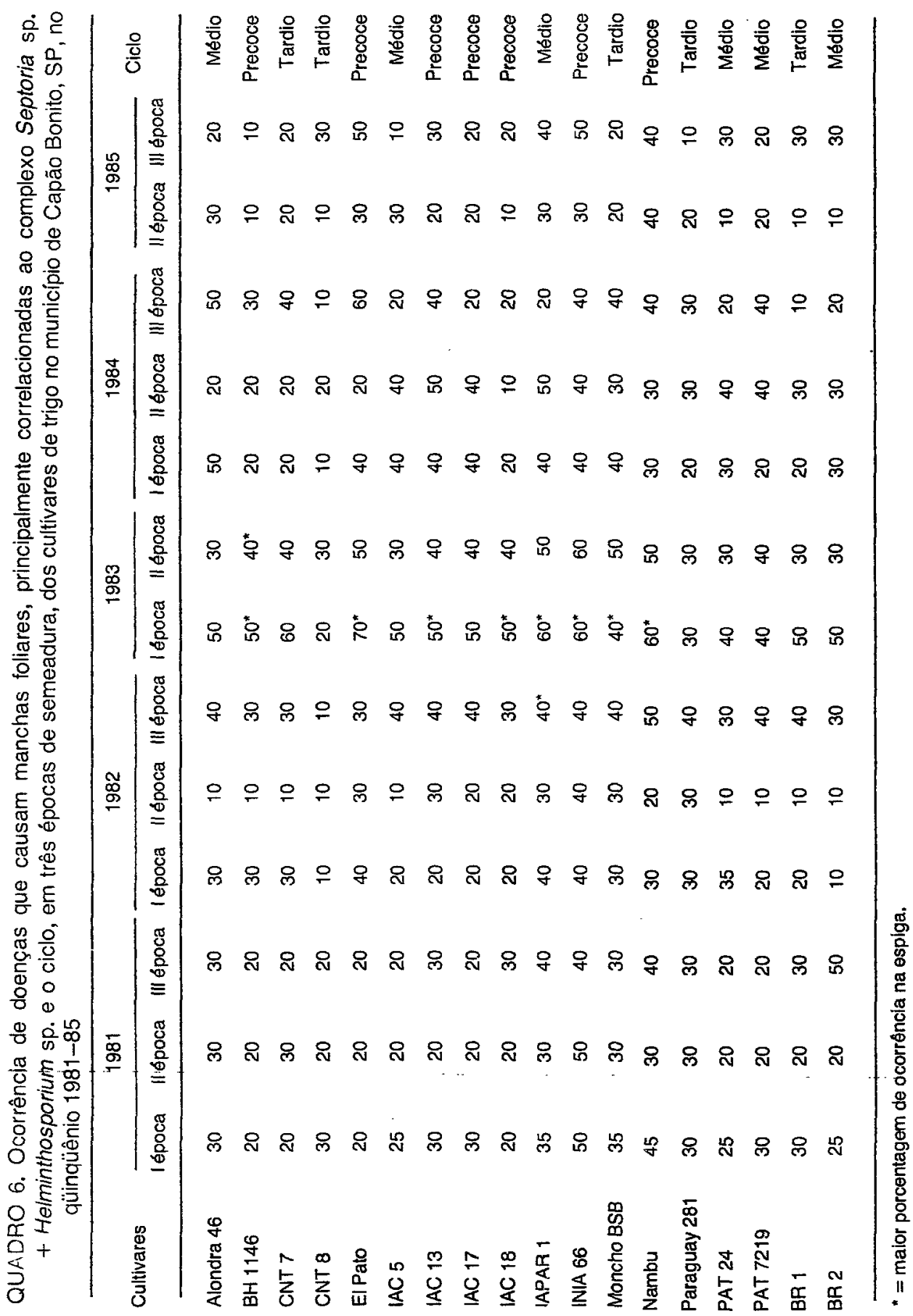


Para a altura média das plantas - Quadro 7 - a análise estatística apresentou efeito altamente significativo para iratamento, $\vartheta=4,36$, mostrando que pelo menos um contraste entre médias não é nulo; 'PAT 24' apresentou o porte mais alto, $104 \mathrm{~cm}$, e o 'El Pato', o mais baixo, $63 \mathrm{~cm}$. O efeito das épocas de semeadura apresentou-se altamente significativo, $\vartheta=2,31$. A maior altura das plantas foi encontrada para a $2^{2}$ época, que não diferiu da $1^{a}$ pelo teste de Duncan a $5 \%$. Ao correlacionar-se a altura média dos cultivares com a produção de grāos para cada época, obtiveram-se somente associaçōes significativas para a $1^{\mathrm{a}}$ e $2^{\mathrm{a}}$ época, mostrando que os cultivares que apresentaram porte mais alto foram também os de melhores produçōes. Considerando a $3^{\text {a }}$ época, não houve correlação significativa $(r=0,256)$, indicando que a altura da planta não influenciou na produtividade.

A análise conjunta das épocas estudadas - Quadro 8 - quanto ao peso hectolítrico, apresentou efeitos altamente significativos para cultivares e para épocas. As médias da $1^{a}$ e da $2^{a}$ época não diferiram entre si, sendo que a $3^{a}$ apresentou o índice de peso hectolítrico mais baixo, diferindo, portanto, das outras pelo teste de Duncan a $5 \%$.

No quadro 9 , encontra-se o peso de mil sementes obtido dos ensaios semeados entre 1981 e 1984. A análise conjunta desses dados demonstrou efeito altamente significativo para cultivares e época. O peso médio de mil grãos, na primeira época, foi de 34,22 gramas, diferindo da $2^{\text {a }}$ época, com um peso médio de 32,00 gramas, e esta diferiu da $3^{a}$ época, com peso médio de 27,01 gramas, pelo teste de Duncan a 5\%. Entre os cultivares estudados o 'El Pato' apresentou o menor peso de mil sementes e o 'PAT 24', o maior.

No quadro 10, encontram-se as correlaçōes entre as médias de produção de grãos dos cultivares no qüinqüênio, independente da época de plantio, e a altura média, o peso hectolítrico e o peso de mil sementes e as correlações entre o peso de mil sementes e o peso hectolítrico. Considerando a correlação entre a produção de grãos e a altura média das plantas, os cultivares IAC 17 e BR 1 apresentaram correlaçōes positivas e significativas ao nivel de $5 \%$, demonstrando que, para esses cultivares, a altura da planta influenciou no rendimento de grão. Por outro lado, a correlação obtida entre a produção de grãos e o peso hectolítrico demonstrou que o peso hectolítrico não influenciou no rendimento dos cultivares BH 1146, CNT 8, El Pato, IAC 18, INIA 66, Moncho BSB e PAT 7219. A correlação entre a produção e o peso de mil sementes apresentou resultado significativo para todos os cultivares, mostrando ser o peso de mil sementes um dos componentes da produção para o qual se deve dar maior atenção. A correlação entre o peso hectolítrico e o peso de mil sementes no qüinqüênio somente nāo foi significativa para o 'El Pato'. Este cultivar apresentou correlação significativa entre produçāo e peso de mil sementes. $O$ peso de mil sementes, à vista dos dados obtidos no presente trabalho, seria o componente da produção que melhor poderia expressar uma diferença entre os componentes em estudo, para definir o melhor cultivar para determinada época de semeadura. 


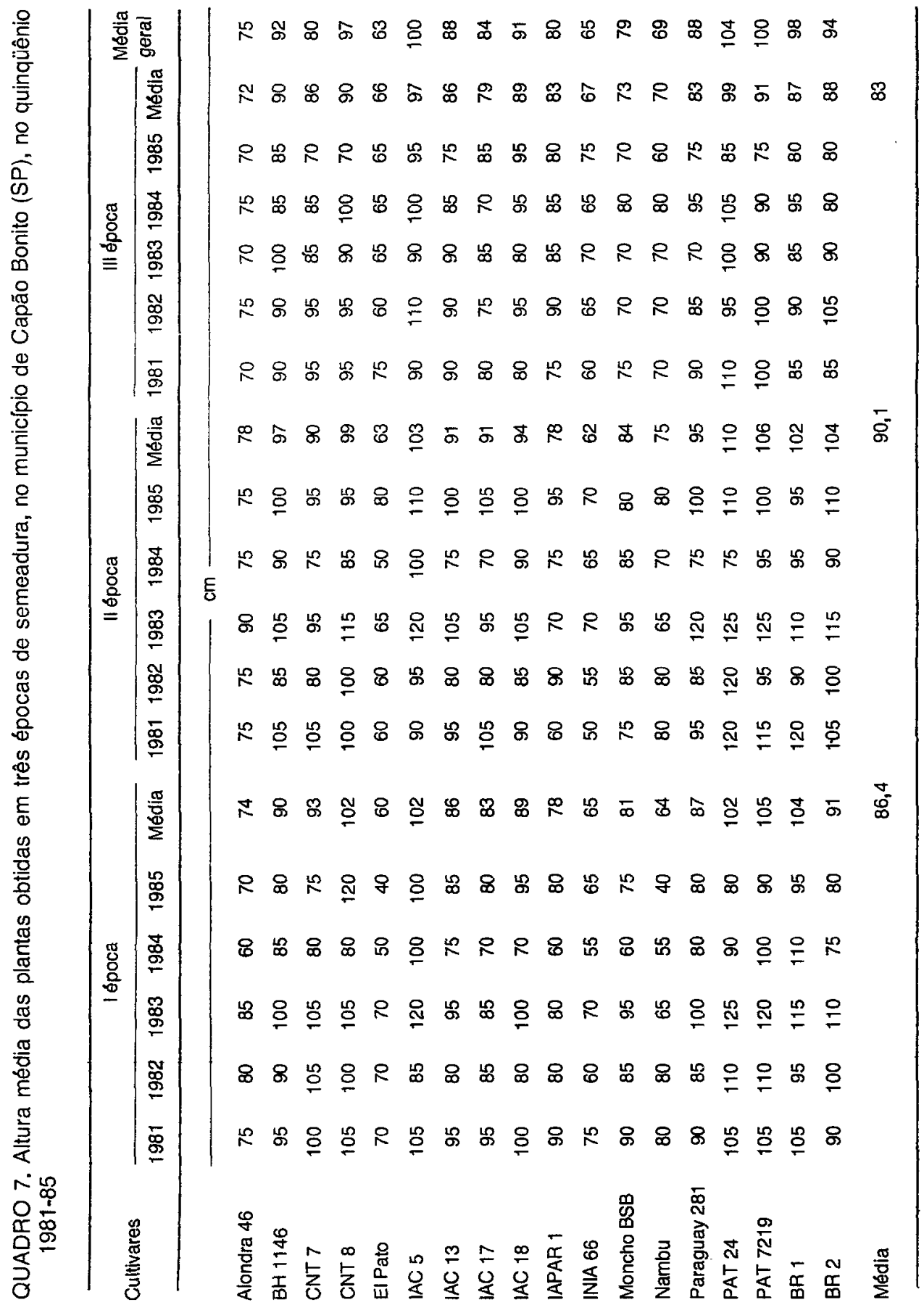




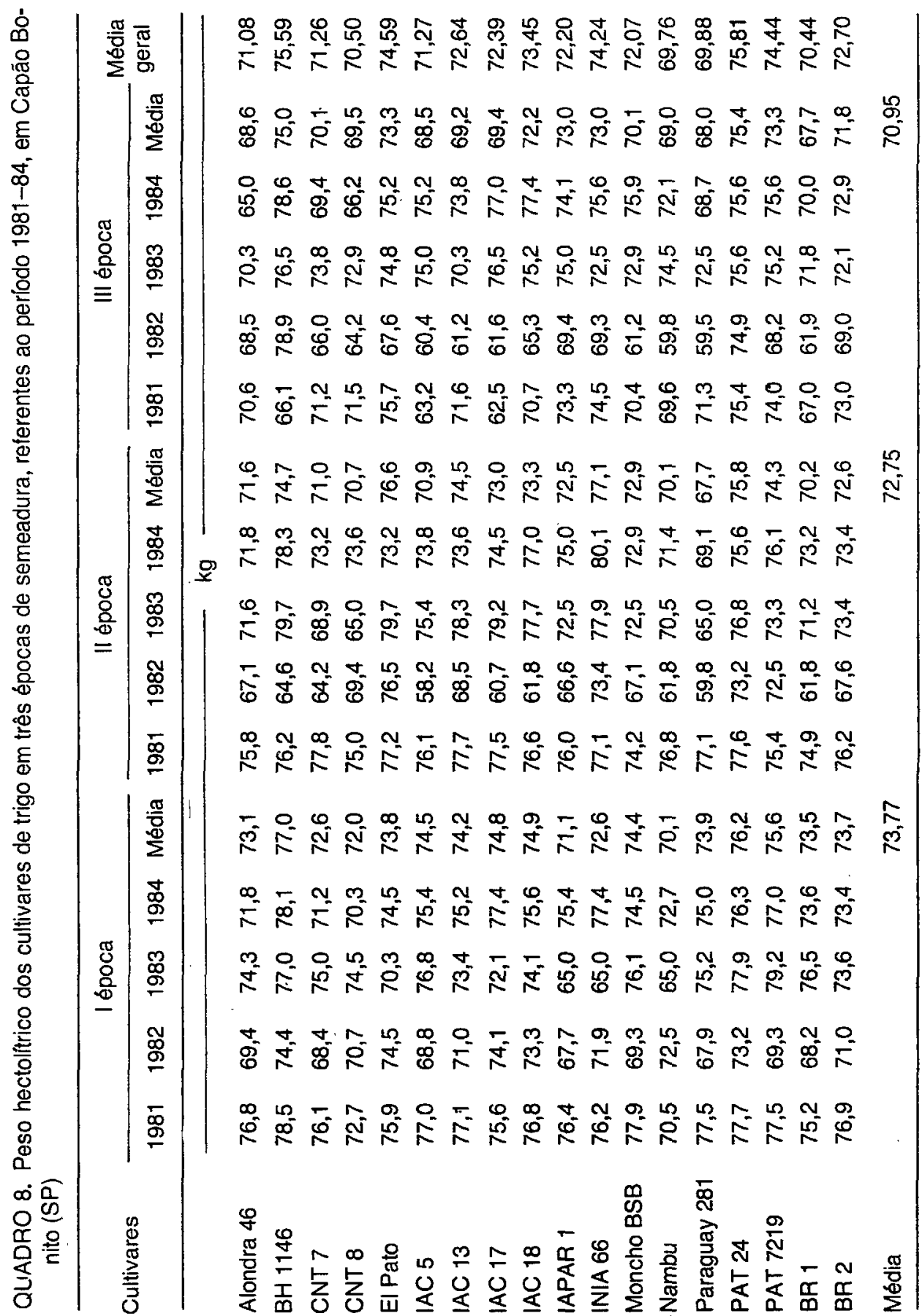




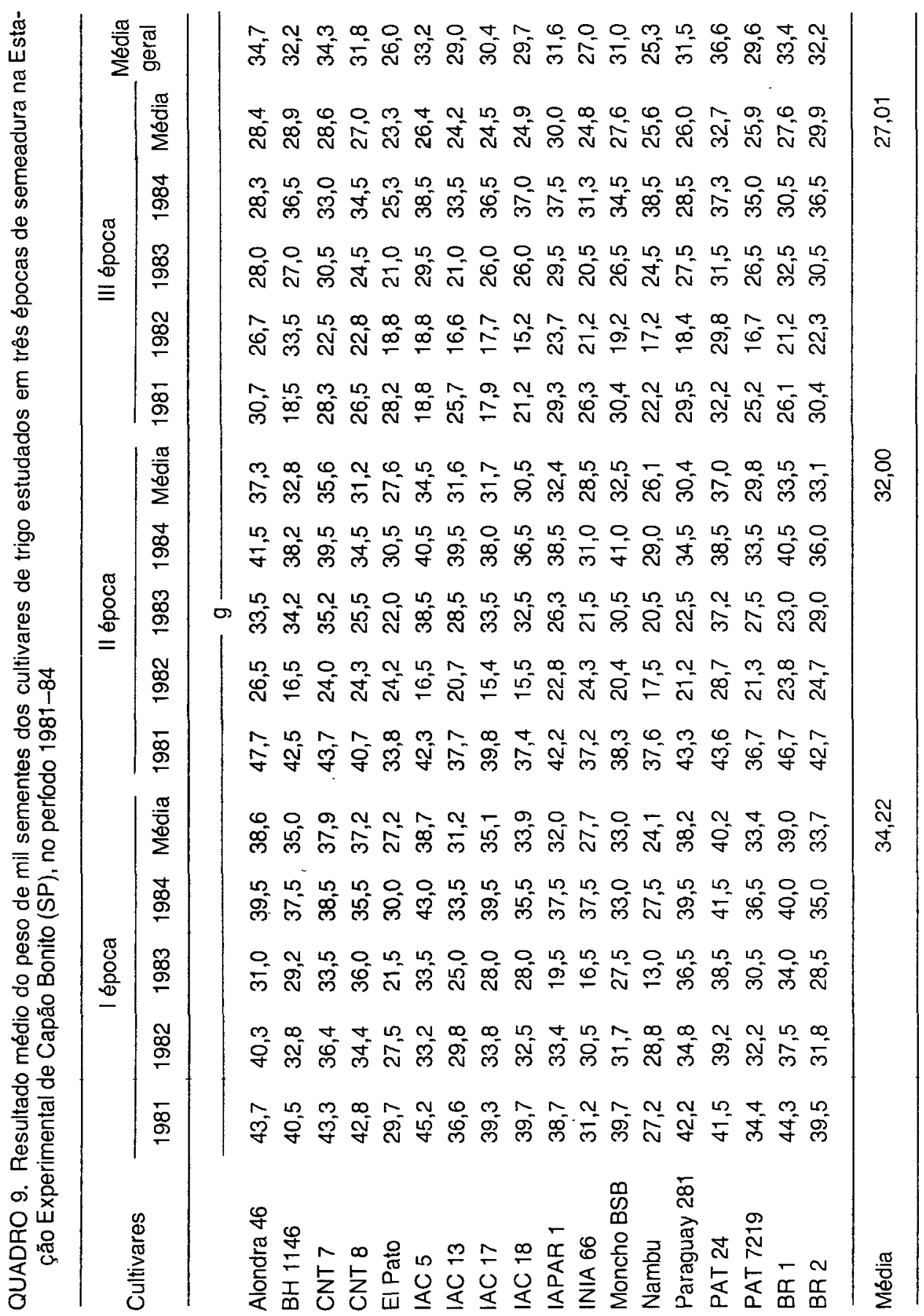


QUADRO 10. Correlação da altura média, peso hectolítrico e peso de mil sementes, com o rendimento de grãos dos cultivares e a correlação do peso de mil sementes e peso hectolítrico

\begin{tabular}{|c|c|c|c|c|}
\hline \multirow{3}{*}{ Cultivares } & \multicolumn{4}{|c|}{ Coeficientes de correlação dos caracteres correlacionados com: } \\
\hline & \multicolumn{3}{|c|}{ Produção de grãos } & \multirow{2}{*}{$\frac{\text { Peso de mil sementes }}{\text { Peso hectolítrico }}$} \\
\hline & Altura & $\begin{array}{c}\text { Peso } \\
\text { hectolitrico }\end{array}$ & $\begin{array}{c}\text { Peso } \\
\text { de mil sernentes }\end{array}$ & \\
\hline Alondra 46 & $0,12 \mathrm{NS}$ & $0,69^{\star}$ & $0,75^{\star \star}$ & $0,71^{* *}$ \\
\hline $\mathrm{BH} 1146$ & $0,23 \mathrm{NS}$ & $0,30 \mathrm{NS}$ & $0,67^{\star \star}$ & $0,84^{\star \star}$ \\
\hline CNT 7 & $0,47 \mathrm{NS}$ & $0,69^{*}$ & $0,74^{\star *}$ & $0,74^{\star \star}$ \\
\hline CNT 8 & 0,44 NS & $0,52 \mathrm{NS}$ & $0,80^{\star *}$ & $0,67^{\star}$ \\
\hline El Pato & $0,03 \mathrm{NS}$ & $0,39 \mathrm{NS}$ & $0,71^{\star \star}$ & $0,40 \mathrm{NS}$ \\
\hline IAC 5 & $-0,21 N S$ & $0,57^{\star}$ & $0,72^{\star \star}$ & $0,90^{\star \star}$ \\
\hline IAC 13 & $0,31 \mathrm{NS}$ & $0,61^{*}$ & $0,70^{*}$ & $0,77^{* *}$ \\
\hline IAC 17 & $0,60^{*}$ & $0,61^{*}$ & $0,78^{\star \star}$ & $0,89^{\star \star}$ \\
\hline IAC 18 & $0,29 \mathrm{NS}$ & $0,52 \mathrm{NS}$ & $0,71^{* *}$ & $0,90^{\star *}$ \\
\hline IAPAR 1 & 0,03 NS & $0,65^{\star}$ & $0,82^{\star \star}$ & $0,79^{\star \star}$ \\
\hline INIA 66 & $0,06 \mathrm{NS}$ & $0,54 \mathrm{NS}$ & $0,77^{\star \star}$ & $0,68^{\star}$ \\
\hline Moncho BSB & 0,12 NS & 0,42 NS & $0,59^{\star}$ & $0,72^{\star \star}$ \\
\hline Nambu & $0,19 \mathrm{NS}$ & $0,63^{*}$ & $0,87^{\star \star}$ & $0,77^{\star \star}$ \\
\hline Paraguay 281 & 0,45 NS & $0,72^{* *}$ & $0,83^{\star \star}$ & $0,89^{* *}$ \\
\hline PAT 24 & $0,26 \mathrm{NS}$ & $0,61^{*}$ & $0,69^{* *}$ & $0,60^{*}$ \\
\hline PAT 7219 & $0,23 \mathrm{NS}$ & $0,50 \mathrm{NS}$ & $0,76^{\star \star}$ & $0,62^{*}$ \\
\hline BR 1 & $0,53^{\star}$ & $0,60^{\star}$ & $0,81^{\star \star}$ & $0,75^{* \star}$ \\
\hline BR 2 & $-0,04$ NS & $0,72^{\star \star}$ & $0,79^{* *}$ & $0,83^{\star \star}$ \\
\hline
\end{tabular}

**Significativo a 1\%. * Significativo a $5 \%$. NS Não significativo.

\section{CONCLUSÕES}

1) A melhor época de semeadura para a cultura do trigo na região de Capāo Bonito foi representada pelo $3^{\circ}$ decêndio de março ( $1^{\text {a }}$ época).

2) Os cultivares de trigo CNT 7, BR 1, Paraguay 281 , CNT 8, BH 1146, IAC 18 e IAC 5 apresentaram as melhores produçōes de grãos na $1^{\text {a }}$ época de semeadura.

3) O melhor ano entre os cinco estudados foi o de 1981, que apresentou as condições climáticas ideais na regiāo para a triticultura. 
4) O 'IAPAR 1' apresentou resistência ao agente causal da ferrugem-dafolha, enquanto os cultivares IAC 5, IAC 13, INIA 66 e PAT 24 exibiram a maior suscetibilidade.

5) Para o agente causal da ferrugem-do-colmo, apresentaram resistência moderada os cultivares CNT 8, INIA 66 e PAT 24, e suscetibilidade, 'BH 1146', 'IAC 5', 'IAC 17', 'IAC 18', 'Nambu' e 'BR 1'.

6) A ocorrência dos agentes causais de manchas foliares nas plantas de trigo foram mais intensas na $3^{a}$ época de semeadura de 1982 e na $1^{\text {a }}$ época de 1983, quando se verificaram as maiores precipitaçōes pluviais na regiāo.

7) As plantas de trigo apresentaram diferença quanto ao porte (altura) em função da época de semeadura.

8) Entre os componentes da produção, peso hectolítrico e peso de mil sementes, este último foi o componente da produção que melhor expressou diferenças entre os cultivares estudados.

\section{SUMMARY}

\section{EVALUATION OF WHEAT CULTIVARS IN THREE SEEDING TIME AT CAPÃO BONITO, STATE OF SÃO PAULO, BRAZIL, DURING THE PERIOD 1981-1985}

This paper presents the behaviour of eighteen wheat cultivars at three seeding times (21. st to 31. st of March, $10^{\text {th }}$ to $20 .^{\text {th }}$ of April and 20 th to $30^{\text {th }}$ of May) in experiments carried out at Capão Bonito Experimental Station, Stafe of São Paulo, Brazil, in the period 1981-1985. Grain yield, disease resistance, plant height, hectolitric weight, 1000 grain weight were evaluated for each experiment. Soil water availability was obtained by water balances taken at each ten days, considering $125 \mathrm{~mm}$ as the soil water retention capacity. The results showed that the seeding time from 21 . st to 31. st of March was the best considering grain yield. The disease occurrence was influenced too much by climatic conditions, meanly caused by Helminthosporium sp. The cultivars CNT 7, BR 1, Paraguay 281, CNT 8, BH 1146, IAC 18 and IAC 5 presented high grain yield at the seeding time from 21 . St to 31. st of March, and it was not found significant differences among them. Fatt varieties exhibited the best grain yield at he first and second seeding times. Grain yield was correlated positively with 1000 grain weight, showing this character to be a good paramether to express the yield potential of a wheat cultivar seeded at three different times.

Index terms: wheat cultivar, water balance, leaf and stern rust, Helminthosporium sp.s plant height, 1000 grain weight. 


\section{REFERÊNCIAS BIBLIOGRÁFICAS}

BARCELLOS, A.L. Ferrugem da folha do trigo no Brasil, população patogênica, fontes de resistência, trigos comerciais, perpetuação e controle químico. In: REUNIÓN DE ESPECIALISTAS EM ROYAS DE CEREAIS DE INVERNO., 13., Passo Fundo, 1985, editado por Carlos L. Molestina. Dialogo. Montevideo; IICA, 1986. p.73-87.

BAYMA, A.C. Trigo. Rio de Janeiro, Serviço de Informaçōes Agrícolas, 1960. 2v. (Estudos Técnicos, 14)

BURGOS, J.J. Las heladas em la Argentina. Buenos Aires, INTA, 1963. 388p. (Colección Cientffica del INTA)

CAMARGO, M.B.P.; ÁRRUDA, H.V.; PEDRO JÜNIOR, M.J.; BRUNINI, O. \& ALFONSI, R.R. Melhores épocas de plantio do trigo no Estado de São Paulo baseadas na probabilidade de atendimento hídrico. Bragantia, Campinas, 44(1):255-261, 1985.

COELHO, E.T. Ferrugem do trigo no Brasil, de 1983 a 1985. In: REUNIAO NACIONAL DE PESQUISA DE TRIGO, 14., Londrina, 1986. p.93-100. (EMBRAPA/CNPT, Documentos, 8)

FELÍCIO, J.C.; BARROS, B.C.; FERREIRA FILHO, A.W.P. \& CASTRO, J.L. Ensaios comparativos de cultivares de trigo em diferentes regiōes paulistas no biênio 1979/80. Bragantia, Campinas, 45(1):1-14, 1986.

GOMES, F.P. Curso de estatística experimental. Piracicaba, Escola Superior de Agricultura "Luiz de Queiroz", 1970. 430p.

KALCKMANN, R.E.; ARRUDA, A.A.G.; HOETGEBAUM, F.; POPA, W.; BALDANZI, G. \& GODOY, L.C. de. Regiōes de trigo no Brasil. $1^{a}$ aproximação agrícola. Pelotas, Serviço Gráfico do IBGE, 1965. 104p. (Estudos técnicos, 28)

LUZ, W.C. da. Influência do perlodo de umidificação pós-inoculaçāo na reação de cultivares de trigo à mancha foliar (Cochliobolus sativus). In: REUNIÄO NACIONAL DE PESQUISA DE TRIGO, 12., Cascavel, 1982. Anais. p.186-191.

MOTA, F.F. da. Clima e zoneamento para a triticultura no Brasil. In: TRIGO no Brasil. Campinas, Fundação Cargill, 1982. v.1, p.29-92.

PAULSEN, G.M. Effect of photoperiod and temperature on cold hardening in winter wheat. Crop Science, 8:29-32, 1968.

SCHARAM, W.; FULCO, W.S.; SOARES, M.H.G. \& ALMEIDA, A.W.P. Resistência de cultivares de trigo em experimentaçāo ou cuitivo no Rio Grande do Sul, às principais doenças fúngicas. Agronomia Sul Rio-Grandense, Porto Alegre, 10:31-39, 1974.

TEIXEIRA, E.F. O trigo no Sul do Brasil. São Paulo, Editora Linotype, 1958. 300p.

THORNTHWAITE, C.W. \& MATHER, J.R. The water balance. Centerton, N.J., Drexel Institute of Technology, 1955. 104p. (Publications in Climatology, v.8, $n=1$ ) 